\title{
Development of a Grafting Method and Healing Conditions to Improve Cabbage Head Quality
}

\author{
Yi-Chen Chen ${ }^{1}$, Wei-Chun Chang ${ }^{1}$, San-Tai Wang ${ }^{2}$, and \\ Shu-I Lin ${ }^{1,3}$
}

AdDitional InDEX wORDs. acclimatization, Brassica olevacea Capitata group, B. oleracea Alboglabra group, head traits, tube grafting

SUMMARY. Grafting is widely used in the commercial production of cucurbits (Cucurbitaceae) and solanaceous (Solanaceae) vegetables, but seldom in the production of cruciferous vegetables such as cabbage (Brassica olevacea Capitata group). In our study, we developed a tube grafting method for cabbage using the 'K-Y cross' cabbage as the scion and 'Tsuei Jin' chinese kale (B. olevacea Alboglabra group) as the rootstock (K-Y/TJ), and then used the K-Y/TJ grafted seedlings to identify the best healing conditions. The examined healing conditions included temperature $\left(15,20\right.$, or $\left.25^{\circ} \mathrm{C}\right)$, relative humidity $(\mathrm{RH} ; 75 \%, 85 \%$, or $95 \%)$, and light intensity (high light intensity, 79 to $107 \mu \mathrm{mol} \cdot \mathrm{m}^{-2} \cdot \mathrm{s}^{-1}$; low light intensity, 38.6 to $58.8 \mu \mathrm{mol} \cdot \mathrm{m}^{-2} \cdot \mathrm{s}^{-1}$; or full darkness, $\left.0 \mu \mathrm{mol} \cdot \mathrm{m}^{-2} \cdot \mathrm{s}^{-1}\right)$. Considering all the healing conditions, the $\mathrm{K}-\mathrm{Y} / \mathrm{TJ}$ grafted seedlings healing at $20^{\circ} \mathrm{C}, 95 \% \mathrm{RH}$, and high light intensity exhibited survival rates of up to $96.7 \%$ and overall superior seedling quality. ' $\mathrm{K}-\mathrm{Y}$ cross' cabbages were then grafted onto chinese kale rootstocks, and the head traits of all grafted plants were comparable to those of nongrafted and/or self-grafted ' $\mathrm{K}-\mathrm{Y}$ cross' plants. ' $\mathrm{K}-\mathrm{Y}$ cross' plants grafted on 'Jie Lan' chinese kale rootstocks had greater ascorbic acid and total soluble solid (TSS) contents than nongrafted and self-grafted ' $K-Y$ cross' plants. Overall, this research describes a successful tube grafting method and the optimal healing conditions for grafted cabbage seedlings, which can be used as a tool to improve head quality.

G rafting is an old but common horticultural technique in which plant tissues from separate plants are joined together to form a new composite plant (Hartmann et al., 201 1; Lee and Oda, 2010). The most well-known function of grafting is improving the soil-borne disease resistance of the new composite plants (Davis et al., 2008a, 2008b; Lee, 1994; Sakata et al., 2007). The prohibition of methyl bromide has further increased the popularity of

Received for publication 17 Sept. 2018. Accepted for publication 10 Dec. 2018.

Published online 31 January 2019.

This work was supported by grants from the Ministry of Science and Technology (MOST 105-2311-B-002-026 and MOST 107-2313-B-002-025) of the Republic of China to S.-I.L.

We thank Yuchia Seed Co., Ltd. for kindly providing elastic grafting tubes.

${ }^{1}$ Department of Horticulture and Landscape Architecture, National Taiwan University, No. 1, Sec. 4 Roosevelt Road, Taipei 10617, Taiwan

${ }^{2}$ Fengshan Tropical Horticultural Experiment Branch, Taiwan Agricultural Research Institute, Council of Agriculture, No. 530, Wenlong E. Road, Fengshan District, Kaohsiung City 83052, Taiwan

${ }^{3}$ Corresponding author. E-mail: shuilin@ntu.edu.tw.

This is an open access article distributed under the CC BY-NC-ND license (https://creativecommons.org/ licenses/by-nc-nd/4.0/).

https://doi.org/10.21273/HORTTECH04193-18 grafting as an alternative approach to disease control (Davis et al., 2008a, 2008b; Oda, 2007; Passam et al., $2005)$. Furthermore, grafting can provide other advantages to the new composite plants, such as improved tolerance to abiotic stresses (e.g., water stress, thermal stress, salt stress, heavy metal toxicity), increased water and nutrient uptake, greater plant vigor, increased yield, and the induction or promotion of flowering (Davis et al., 2008b; Lee, 1994; Lee and Oda, 2010; Lee et al., 2010; Oda, 2007; Rivero et al., 2003; Schwarz et al., 2010). Vegetable grafting is already widely used for commercial production of cucurbitaceous vegetables [e.g., watermelon (Citrullus lanatus), cucumber (Cucumis satious), melon (Cucumis melo)] and solanaceous crops [e.g., eggplant (Solanum melongena), pepper (Capsicum annuum), tomato (Solanum lycopersicum)] (Gaion et al., 2017; Lee et al., 2010; Schwarz et al., 2010). The variety of vegetable species for which grafting techniques have been developed has increased (Lee, 1994), and an increasing number of countries are involved in vegetable grafting (Davis et al., 2008a, 2008b; Kubota et al., 2008; Lee et al., 2010; Mudge et al., 2009).

Although grafting culture is commonly used in several vegetables, its application has been generally limited to cucurbits and solanaceous vegetables. The application of grafting techniques to more vegetables is an important issue. Cabbage is an important crop that belongs to the Crucifer family (Brassicaceae) and has never been seedling-grafted for commercial production. Based on a literature survey, we found that cabbage can be grafted onto kale (B. oleracea Acephala group) or kohlrabi (B. oleracea Gongylodes group) rootstock successfully by cleft grafting, but the survival ratios are very low (5\% to $20 \%$ ) (Oda et al., 1992). These low survival ratios may limit the commercial production of grafted cabbage seedlings. Chinese cabbage (Brassica rapa Pekinensis group) was reportedly grafted onto turnip (B. rapa Rapifera group) rootstock by cleft or horizontal methods, with survival ratios of $\approx 50 \%$ (Oda and Nakajima, 1992). The greater survival ratios of chinese cabbage than of cabbage suggests the potential to improve cabbage grafting.

The survival ratios of grafted seedlings depend on the grafting compatibility between scion and rootstock as well as on seedling age and quality, grafting technique, and management after grafting (Andrews and Serrano Marquez, 1993; Davis et al., 2008b; Oda, 2007). Diverse grafting methods have been developed for different vegetables, such

\begin{tabular}{llll}
\hline $\begin{array}{l}\text { Units } \\
\text { To convert U.S. to SI, } \\
\text { multiply by }\end{array}$ & U.S. unit & SI unit & $\begin{array}{l}\text { To convert SI to U.S., } \\
\text { multiply by }\end{array}$ \\
\hline 29.5735 & $\mathrm{fl} \mathrm{oz}$ & $\mathrm{mL}$ & 0.0338 \\
2.54 & inch $(\mathrm{es})$ & $\mathrm{cm}$ & 0.3937 \\
25.4 & inch $(\mathrm{es})$ & $\mathrm{mm}$ & 0.0394 \\
16.3871 & inch & $\mathrm{cm}^{3}$ & 0.0610 \\
28.3495 & $\mathrm{Oz}$ & $\mathrm{g}$ & 0.0353 \\
0.001 & $\mathrm{ppm}$ & $\mathrm{mg} \cdot \mathrm{g}^{-1}$ & 1000 \\
1 & $\mathrm{ppm}$ & $\mathrm{mg} \cdot \mathrm{L}^{-1}$ & 1 \\
$\left({ }^{\circ} \mathrm{F}-32\right) \div 1.8$ & ${ }^{\circ} \mathrm{F}$ & ${ }^{\circ} \mathrm{C}$ & $\left({ }^{\circ} \mathrm{C} \times 1.8\right)+32$
\end{tabular}


as cleft grafting, tongue approach grafting, hole insertion grafting, and splice grafting (Lee, 1994; Lee and Oda, 2010; Lee et al., 2010; Oda, 2007). Among these techniques, tube grafting, also known as slant-cut grafting or splice grafting, can be applied in small plants grown in plugs (Lee and Oda, 2010; Oda, 2007). Tube grafting is a common method for grafted commercial tomato seedling production in Taiwan, and is also popular in Japan, Korea, and the United States for plugcultured tomato seedlings (Lee et al., 2010; Oda, 2007). The tube-grafting procedure is simple and rapid (Lee and Oda, 2010). Importantly, this technique can be performed by hand or by using a grafting robot (Lee and Oda, 2010). Furthermore, the seedlings produced via the grafting method are healthy and strong (Lee and Oda, 2010 ), and there is no need to remove the tube after successful grafting.

Proper acclimatization, which includes healing and hardening, is a very important factor for success after grafting (Jang et al., 2011; Lee and Oda, 2010; Lee et al., 2010; Oda, 2007). Environmental factors related to healing include temperature, $\mathrm{RH}$, and light intensity (Jang et al., 2011; Mudge et al., 2009). Grafted tomato seedlings allowed to heal at $23{ }^{\circ} \mathrm{C}$ had greater survival rates than seedlings that healed at 17,20 , and $26^{\circ} \mathrm{C}$ (Vu et al., 2013). At $14 \mathrm{~d}$ postgrafting, watermelon seedlings that healed at $27.5 \pm 1.5^{\circ} \mathrm{C}$ had greater shoot fresh weight, root fresh weight, and leaf area than those of seedlings healed at $30.5 \pm 1.5^{\circ} \mathrm{C}$ and $33.5 \pm 1.5^{\circ} \mathrm{C}$ (Chang et al., 2003). To prevent scion wilting, low light intensity and high humidity conditions are preferable for healing (Nobuoka et al., 1996). However, greater light intensity during acclimatization improves the quality of grafted tomato and cucumber seedlings (Jang et al., 2011; Nobuoka et al., 2005). Furthermore, grafted tomato seedlings healing at $80 \% \mathrm{RH}$ had greater final survival rates than seedlings healing at $90 \% \mathrm{RH}$ because a lower percentage of diseased plants were found under $80 \% \mathrm{RH}$ conditions ( $\mathrm{Vu}$ et al., 2013). These examples suggest that different plant materials used for grafting require different healing conditions, and the best healing conditions can increase survival rates and improve seedling quality.

In this research, we attempted to develop a cabbage grafting method using tube grafting for potential diverse purposes in the future. First, we evaluated whether the tube-grafting method could be applied to cabbage. Second, we identified the best healing conditions for the grafted cabbage for future commercial production. Last, we determined the effects of grafting on cabbage head traits.

\section{Materials and methods}

Plant MATERIALS AND GROWTH CONDitions. To estimate the survival rate and quality of grafted seedlings, 'K-Y cross' cabbage purchased from Takii \& Co., Ltd. (Kyoto, Japan), was used as the scion, and 'Tsuei Jin' chinese kale from Known-You Seed Co., Ltd. (Kaohsiung, Taiwan), was used as the rootstock. To estimate the yield and head traits of grafted cabbage, 'K-Y cross' cabbage was used as the scion, and chinese kale rootstocks included 'Tsuei Jin', 'Huei Jin', and 'CK-71' from Known-You Seed Co., Ltd.; 'Jen Chiau' and 'Jung Ching' from Po Yu Trading Co., Ltd. (Kaohsiung, Taiwan); 'Jung Gau' from Ching Long Seed Co., Ltd. (Tainan, Taiwan); 'Taichung No. l' from the Taichung District Agricultural Research and Extension Station, Council of Agriculture (Executive Yuan, Taiwan); and 'Jie Lan' from a local breeder in Taiwan. Seeds of the rootstock and scion were surface sterilized using $1 \%$ sodium hypochlorite (Clorox, Kuala Lumpur, Malaysia) with $0.002 \%$ nonionic surfactant (Tween 20; J.T. Baker, Phillipsburg, NJ) for $15 \mathrm{~min}$. After rinsing several times with deionized water, the seeds were sown in plug trays with 72 holes and grown in a phytotron at National Taiwan University (NTU) with 16/ 8 -h light/dark cycles, $25 / 20^{\circ} \mathrm{C}$ day $/$ night temperatures, and a light intensity of $100-120 \mu \mathrm{mol} \cdot \mathrm{m}^{-2} \cdot \mathrm{s}^{-1}$.

Tube grafting. For tube grafting, 2l-d-old seedlings were used as scion and rootstock. For the scions, slant cuts at a 30 to $45^{\circ}$ angle in the stem were made using a razor blade between the first node (where the cotyledon was attached) and the second node [where the first leaves were attached (Fig. 1A)]. The total length of the incision in each scion was 0.3 to $0.5 \mathrm{~cm}$, and the total length of the scion was 0.8 to $1.1 \mathrm{~cm}$. Most mature leaves on the scion were removed to reduce transpiration (Fig. 1A). For the rootstock, slant cuts with a 30 to $45^{\circ}$ angle, the same as the scion, were made (Fig. 1B), and the total length of the incision in each rootstock was also 0.3 to $0.5 \mathrm{~cm}$. The angle of the slant cut was the same as in the scion and rootstock. Next, an elastic grafting tube, which was kindly provided by Yuchia Seed Co., Ltd. (Chiayi, Taiwan), was applied to the cut site of the rootstock, and the scion was inserted into the tube in the same direction to join the scion and rootstock tightly (Fig. IC and D). Depending on the stem diameters, elastic tubes with different diameters (1.9 or $2.3 \mathrm{~mm}$ ) were used. Eventually, the grafted cabbage formed a mature head (Fig. 1E).

Healing process. After grafting, the seedlings were transferred to a growth chamber (CK-68EXD; Chang Kuang, Taipei, Taiwan) for 3 to $5 \mathrm{~d}$ with different healing conditions as follows. For the temperature experiment, grafted seedlings were grown in growth chambers $(95 \%$ $\mathrm{RH}$ and dark) with different temperatures $\left(15,20\right.$, or $\left.25^{\circ} \mathrm{C}\right)$ for $5 \mathrm{~d}$. For the RH experiment, grafted seedlings were grown in growth chambers $\left(20{ }^{\circ} \mathrm{C}\right.$ and dark) with different $\mathrm{RH}$ $(75 \%, 85 \%$, or $95 \%)$ for $5 \mathrm{~d}$. For the light intensity experiment, grafted seedlings were grown in a growth chamber $\left(20{ }^{\circ} \mathrm{C}\right.$ and $\left.95 \% \mathrm{RH}\right)$ with different light intensities (high light intensity, $79-107 \mu \mathrm{mol} \cdot \mathrm{m}^{-2} \cdot \mathrm{s}^{-1}$; low light intensity, 38.6-58.8 $\mu \mathrm{mol} \cdot \mathrm{m}^{-2} \cdot \mathrm{s}^{-1}$; or full darkness, $0 \mu \mathrm{mol} \cdot \mathrm{m}^{-2} \cdot \mathrm{s}^{-1}$ ) for $5 \mathrm{~d}$. Considering space and manpower constraints, we attempted to determine the best conditions for healing with respect to temperature, $\mathrm{RH}$, and light intensity by changing only one factor at a time. When the optimal conditions were found for that factor, the next factor was tested under the previously determined conditions.

Hardening process. An effective hardening process is also important for successful grafting. Therefore, after healing, the grafted plants were transferred to NTU's phytotron, placed in a simple homemade chamber, and covered with a transparent plastic cloth and two layers of $50 \%$ black shade netting for $2 \mathrm{~d}$. The transparent plastic cloth was used to reduce moisture loss, and the black shade netting was used to prevent excessive heat buildup. After $2 \mathrm{~d}$, one layer of black shade netting was removed, and the grafted seedlings were kept inside for another 


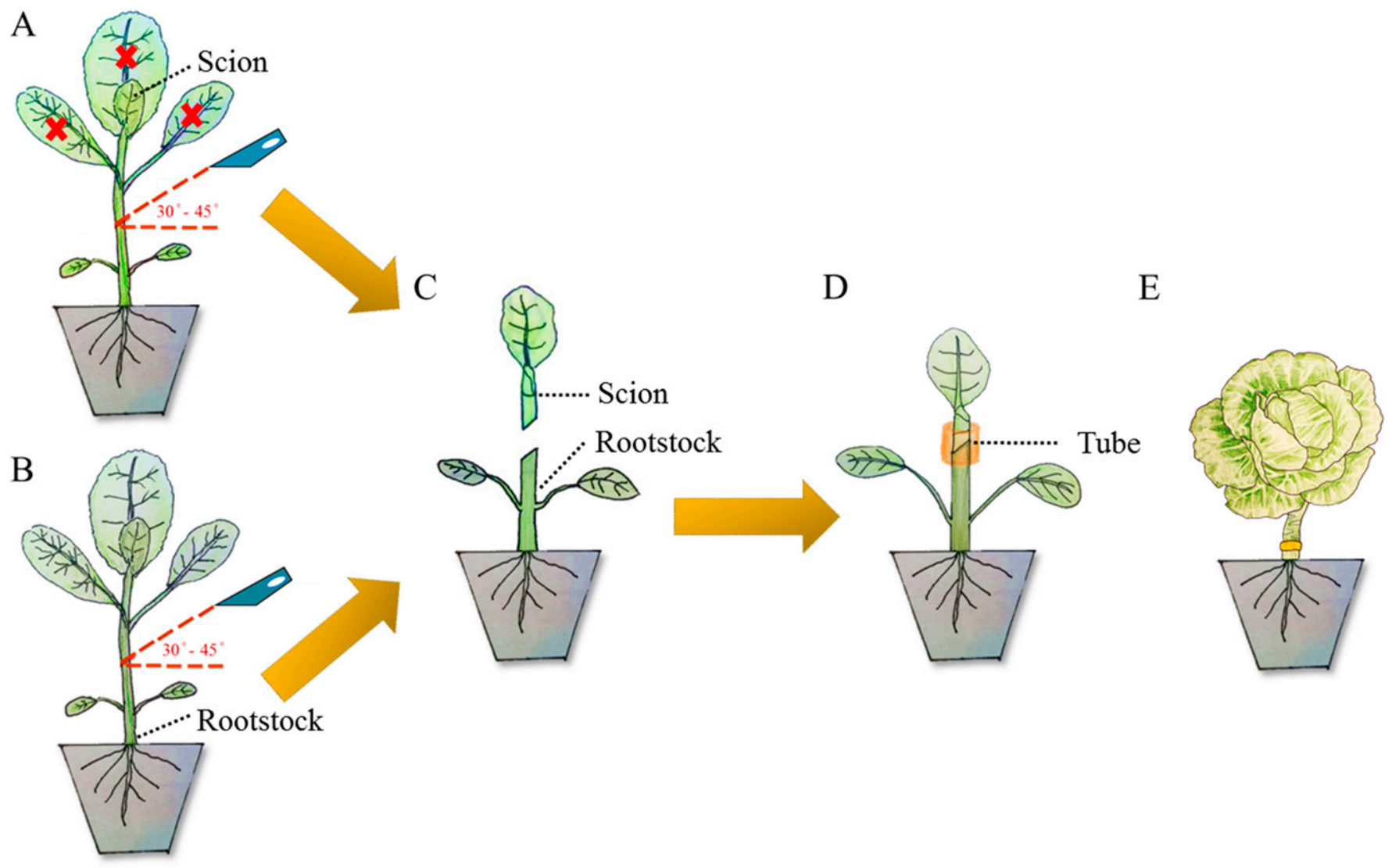

Fig. 1. Schematic of the cabbage tube grafting method. For grafting, 21-d-old cabbage and chinese kale seedlings were used as (A) scion and (B) rootstock, respectively, and diagonal cuts in the stem at 30 to $45^{\circ}$ angles were made in both the scion and rootstock. Most mature leaves in the scion were removed (A) to reduce transpiration. The scion and the rootstock (C) were fixed together (D) using an elastic tube. (E) The grafted cabbage plants later formed mature heads.

$2 \mathrm{~d}$. Then, all black shade netting was removed, and the grafted seedlings remained covered with the transparent plastic cloth for $1 \mathrm{~d}$. Last, the grafted seedlings were grown in NTU's phytotron without any cover.

SURVIVAL RATE AND QUALITY OF GRAFTED SEEDLINGS. The survival rates (measured as a percentage) of the grafted seedlings were monitored after they had been grafted for 3 to $12 \mathrm{~d}$. At $12 \mathrm{~d}$ after grafting, the surviving grafted seedlings were transferred to 3 -inch-diameter pots and grown in NTU's phytotron. At $35 \mathrm{~d}$ after grafting, the surviving grafted seedlings were used to determine the stem diameter, plant height, leaf number, fresh weight, dry weight, and strong seedling index. Stem diameter was determined by measuring the stem diameter $1 \mathrm{~cm}$ above the grafting tube with an electronic Vernier caliper (Mitutoyo, Tokyo, Japan). Plant height was determined by measuring the height from the soil surface to the plant apex. The number of fully expanded leaves was calculated as the leaf number. After the soil attached to the roots was rinsed away and the excess water was absorbed with hand towels, the fresh weight and dry weight of whole seedlings were determined. The fresh weight was determined using an electronic scale (XJ-2100; Denver Instrument, Arvada, CO); the dry weight was determined using an electronic scale (XS204; Mettler Toledo, Zürich, Switzerland) after transferring the seedlings to an oven (DO30; Deng Yng, Taipei, Taiwan) and drying at $80{ }^{\circ} \mathrm{C}$ for $3 \mathrm{~d}$ until a constant weight was achieved. The strong seedling index was calculated according to Chang (2004) using the following formula: strong seedling index $=$ stem diameter (measured in centimeters $) \times$ seedling dry weight (measured in grams) $\times$ leaf number $\div$ seedling height (measured in centimeters).

YIELD AND HEAD TRAITS OF GRAFTED CABBAGE. 'K-Y cross' cabbage was grafted on different rootstocks as described earlier. All seeds were sown on 17 Oct. 2014 and grafted on 7 Nov. 2014 using the previously described tube-grafting method. The surviving grafted seedlings were transplanted to 10 -inchdiameter pots (L-046; Dah-Maan Bio-Tech Co., Kaohsiung, Taiwan) on 1 Dec. 2014 and were grown in the greenhouse at NTU with a pad and fan system. On 2 May 2015, the cabbages were harvested to determine the yield and head traits. The temperature and photosynthetically active radiation $(P A R)$ in the greenhouse from 1 Dec. 2014 to 2 May 2015 are shown in Supplemental Fig. 1. The average temperature was 17 to $25^{\circ} \mathrm{C}$, and PAR was supplied at 3439 to $8374 \mu \mathrm{mol} \cdot \mathrm{m}^{-2} \cdot \mathrm{s}^{-1}$ during the cultivation period.

After removing one to two outer leaves, the head weight was determined using an electronic scale (XJ2100). The head polar diameter, head equatorial diameter, head volume, core length, core base width, and percentage of head volume were determined according to a previous 
study (Kleinhenz and Wszelaki, 2003). The head was then sliced into several parts. The juice was extracted from one part of the head using a juicer (MJ-M171P; Panasonic, Shah Alam, Malaysia), and centrifuged at $3880 \mathrm{~g}_{\mathrm{n}}$ and $4^{\circ} \mathrm{C}$ for $10 \mathrm{~min}(\mathrm{z} 326 \mathrm{k}$; Hermale, Wehingen, Germany). The supernatant was used to determine the ascorbic acid and TSS contents. The ascorbic acid content was measured with ascorbic acid test strips (Reflectoquant $^{\circledR}$; Merck, Darmstadt, Germany) and a reflectometer (RQflex Plus 10, Merck) according to the manufacturer's instructions. The TSS content was measured with a hand refractometer $(\mathrm{Nl}$; Atago, Tokyo, Japan) according to the manufacturer's instructions. Another part of the head was weighed and baked in an $80^{\circ} \mathrm{C}$ circulator oven (DO30) for $3 \mathrm{~d}$ until a constant weight was obtained. Dried samples were weighed (XS204). The water content was calculated using the method of a previous study (Garnier and Laurent, 1994), using the following formula: water content $=($ fresh weight - dry weight $) \div$ fresh weight. A part of the head was frozen in liquid nitrogen and ground with a mortar and pestle. The total chlorophyll content was determined according to a previously described method (Arnon, 1949; Razaq et al., 2017; Xiang et al., 2011), with minor modifications. Briefly, $0.2 \mathrm{~g}$ frozen homogenate was mixed with $12 \mathrm{~mL} \mathrm{95 \%}$ ethanol and incubated at $68{ }^{\circ} \mathrm{C}$ in a thermostatic water bath (BU410D; Yih Der, Taipei, Taiwan) for $2 \mathrm{~h}$. After centrifugation at $3880 g_{\mathrm{n}}$ for $10 \mathrm{~min}, 1 \mathrm{~mL}$ supernatant was used to quantify the chlorophyll content in a spectrophotometer (U-5100; Hitachi, Tokyo, Japan) at 665 and $649 \mathrm{~nm}$. The concentration of chlorophyll was calculated using the following formulas: chlorophyll a $(\mathrm{Chl}$ a $)=13.95 \mathrm{~A}_{665}-6.88 \mathrm{~A}_{649}$; chlorophyll $\mathrm{b}(\mathrm{Chl} \mathrm{b})=24.96 \mathrm{~A}_{649}-$ $7.32 \mathrm{~A}_{665}$; and total chlorophyll $=$ $\mathrm{Chl} \mathrm{a}+\mathrm{Chl} b$.

EXPERIMENTAL DESIGN AND STATISTICAL ANALYSIS. For survival rate analysis, each treatment contained 30 plants. After grafting, 10 surviving grafted plants were selected randomly for seedling quality analysis. To estimate the yield and head traits of grafted plants, a randomized complete block design was used. Each treatment included four replicates and each replicate had two plants. Values are expressed as the mean $\pm \mathrm{SD}$. Analysis of variance was performed using CoStat 6.2 software (CoHort Software, Monterey, CA), and differences among treatments were determined at $P \leq 0.05$ by Fisher's protected least significant difference test.

\section{Results}

Temperature effects. 'K-Y cross', the major cabbage cultivar in Taiwan, was used as the scion in this research. Chinese kale was selected as the rootstock because it belongs to the Brassica family and has low seed cost, high plant vigor, and a stem diameter similar to that of cabbage. Furthermore, nonspecific stem resistance to black rot disease (caused by Xanthomonas campestris) was found previously in chinese kale (Ignatov et al., 1998). To evaluate graft healing conditions in this study, 'Tsuei Jin' chinese kale was selected as the rootstock because it has a uniform appearance and high plant vigor. Using the tube-grafting method described earlier, we grafted 'K-Y cross' cabbage successfully onto 'Tsuei Jin' chinese kale (Fig. 2A). To evaluate the effect of healing temperature, the grafted ' $\mathrm{K}-\mathrm{Y}$ cross' seedlings were allowed to heal at 15,20 , and $25{ }^{\circ} \mathrm{C}$ for $5 \mathrm{~d}$ at $95 \% \mathrm{RH}$ in dark conditions, and their survival rates were evaluated $3,5,6,9$, 10 , and $12 \mathrm{~d}$ after grafting. Grafted seedlings healing at $15{ }^{\circ} \mathrm{C}$ had the greatest survival rate, with survival rates of $100 \%$ from days 3 to 12 after grafting (Table 1). The survival rates of grafted seedlings healing at 20 and $25^{\circ} \mathrm{C}$ were also at $100 \%$ on days 3 and 5 after grafting, but decreased gradually over the subsequent days (Table 1 ). On day 12 after grafting, the seedlings healing at $20^{\circ} \mathrm{C}$ had survival rates up to $96.7 \%$, but the survival rates of seedlings healing at $25{ }^{\circ} \mathrm{C}$ decreased to $93.3 \%$ (Table 1 ).

Next, we examined the quality of 'K-Y cross' grafted seedlings on day 35 after grafting. Seedlings that had healed at $20^{\circ} \mathrm{C}$ had the largest stem diameters, tallest plant heights, and greatest values for fresh weight, dry weight, leaf number, and strong seedling index (Table 2). Considering the survival rate of ' $\mathrm{K}-\mathrm{Y}$ cross' grafted seedlings healed at 15 and $20{ }^{\circ} \mathrm{C}$, both were greater than $95 \%$, but seedlings healed at $20^{\circ} \mathrm{C}$ had better quality than those healed at $15{ }^{\circ} \mathrm{C}$; therefore, we chose $20^{\circ} \mathrm{C}$ for the next experiment.

RH EFFECTS. We then examined the effect of RH on the ' $\mathrm{K}-\mathrm{Y}$ cross' grafted seedlings by allowing the grafted seedlings to heal at $75 \%$, $85 \%$, and $95 \% \mathrm{RH}$ for $5 \mathrm{~d}$ at $20^{\circ} \mathrm{C}$ under dark conditions. Grafted seedlings that had healed at $85 \% \mathrm{RH}$ had the greatest survivorship, with survival rates of $100 \%$ from days $3-12$ after grafting (Table 3 ). The survival rate of grafted seedlings allowed to heal at $95 \% \mathrm{RH}$ was also $100 \%$ on days 3 to 9 after grafting, but decreased slightly to $96.7 \%$ on days 10 and 12 (Table 3 ). The survival rate of grafted seedlings that had healed at $75 \% \mathrm{RH}$ was $100 \%$ on day 3 only, then decreased gradually through subsequent days, with only a $93.3 \%$ survival rate on day 12 (Table 3).

When evaluating the effects of $\mathrm{RH}$ on the quality of ' $\mathrm{K}-\mathrm{Y}$ cross' grafted seedlings, we found that different $\mathrm{RH}$ treatments had no significant effect on stem diameter or leaf number (Table 4). However, 'K-Y cross' grafted seedlings healed at $95 \% \mathrm{RH}$ had the greatest values for plant height, fresh weight, dry weight, and strong seedling index (Table 4).

Because the survival rates of ' $\mathrm{K}-\mathrm{Y}$ cross' grafted seedlings healed at $85 \%$ and $95 \% \mathrm{RH}$ were both high (>95\%), whereas seedlings healed at $95 \% \mathrm{RH}$ had greater fresh weight, dry weight, and strong seedling index than those healed at $85 \% \mathrm{RH}$, we selected $95 \%$ $\mathrm{RH}$ for the subsequent experiments.

LIGHT INTENSITY EFFECTS. ' $\mathrm{K}-\mathrm{Y}$ cross' grafted seedlings were healed at $20{ }^{\circ} \mathrm{C}$ and $95 \% \mathrm{RH}$ for $5 \mathrm{~d}$ in highlight $\left(79-107 \mu \mathrm{mol} \cdot \mathrm{m}^{-2} \cdot \mathrm{s}^{-1}\right)$, lowlight $\left(38.6-58.8 \mu \mathrm{mol} \cdot \mathrm{m}^{-2} \cdot \mathrm{s}^{-1}\right)$, or dark $\left(0 \mu \mathrm{mol} \cdot \mathrm{m}^{-2} \cdot \mathrm{s}^{-1}\right)$ environments. For 'K-Y cross' grafted seedlings healed under high-light conditions, the survival rate was $96.7 \%$ for 3 to 12 d postgrafting (Table 5 ). When ' $\mathrm{K}-\mathrm{Y}$ cross' grafted seedlings were allowed to heal under low-light conditions, they maintained the $96.7 \%$ survival rate for 3 to $9 \mathrm{~d}$ after grafting, but the survival rate decreased to $93.3 \%$ on days 10 and 12 after grafting (Table 5). When 'K-Y cross' grafted seedlings were allowed to heal under dark conditions, although they had a $100 \%$ survival rate for 3 to $9 \mathrm{~d}$ after grafting, the survival rate decreased to 
A

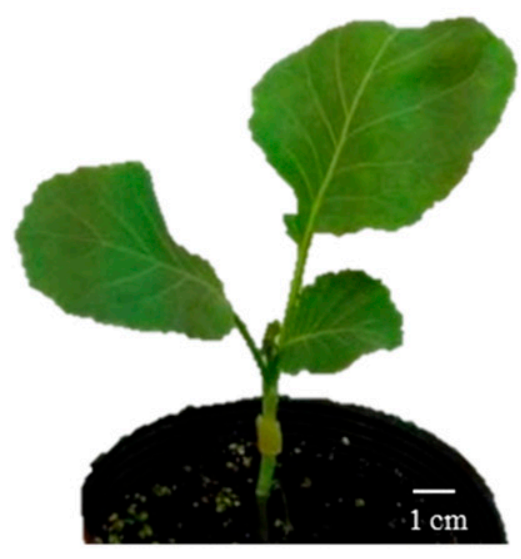

$\mathrm{B}$

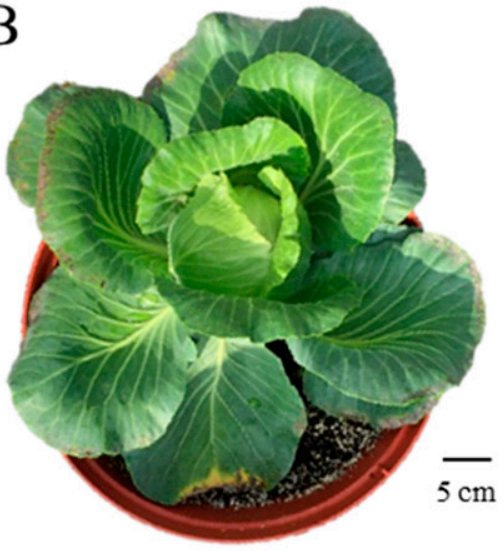

$\mathrm{K}-\mathrm{Y} / \mathrm{K}-\mathrm{Y}$

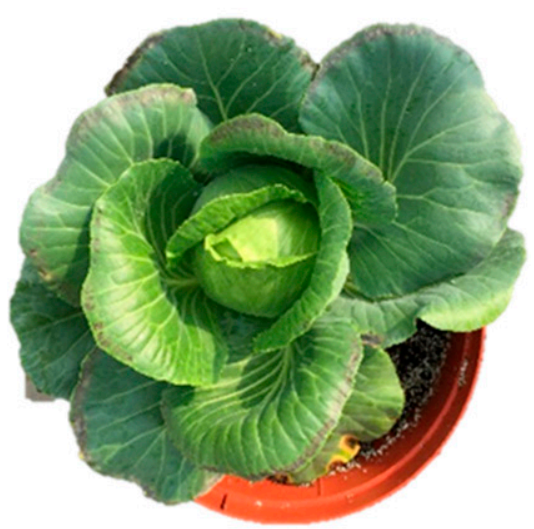

$\mathrm{K}-\mathrm{Y} / \mathrm{TJ}$

Fig. 2. Seedling appearance (A) and mature head appearance (B) of grafted cabbage. (A) Seedling appearance of 'K-Y cross' cabbage grafted on 'Tsuei Jin' chinese kale for $17 \mathrm{~d}$. (B) Mature heads formed at 18 weeks after grafting in self-grafted 'K-Y cross' plants (K-Y/K-Y) and 'K-Y cross' cabbage scion grafted on 'Tsuei Jin' chinese kale rootstock $(\mathrm{K}-\mathrm{Y} / \mathrm{TJ})$. Bar $=5 \mathrm{~cm}(2.0$ inches).

Table 1. Effect of healing chamber temperature on the survival rate of grafted cabbage seedlings grown in a growth chamber (with $95 \%$ relative humidity in darkness) at different temperatures for $5 \mathrm{~d}(\mathbf{n}=\mathbf{3 0})$.

\begin{tabular}{lccrrrr}
\hline & \multicolumn{7}{c}{ Time after grafting $(\mathbf{d})$} \\
\cline { 2 - 7 } Temp $\left({ }^{\circ} \mathbf{C}\right)^{\mathrm{z}}$ & $\mathbf{3}$ & $\mathbf{5}$ & $\mathbf{6}$ & $\mathbf{9}$ & $\mathbf{1 0}$ & $\mathbf{1 2}$ \\
\cline { 2 - 7 } & 100.0 & 100.0 & 100.0 & 100.0 & 100.0 & 100.0 \\
15 & 100.0 & 100.0 & 100.0 & 100.0 & 96.7 & 96.7 \\
25 & 100.0 & 100.0 & 96.7 & 96.7 & 96.7 & 93.3 \\
\hline
\end{tabular}

${ }^{\mathrm{z}}\left(1.8 \times{ }^{\circ} \mathrm{C}\right)+32={ }^{\circ} \mathrm{F}$.

Table 2. Effect of healing chamber temperature on the subsequent growth of 35-d-old grafted cabbage seedlings.

\begin{tabular}{|c|c|c|c|c|c|c|c|c|c|c|c|c|}
\hline \multirow{2}{*}{$\frac{\operatorname{Temp}\left({ }^{\circ} \mathrm{C}\right)^{\mathrm{z}}}{15}$} & \multicolumn{2}{|c|}{$\begin{array}{c}\text { Stem } \\
\operatorname{diam}(\mathrm{cm})^{\mathrm{z}}\end{array}$} & \multicolumn{2}{|c|}{$\begin{array}{c}\text { Plant } \\
\text { ht }(\mathrm{cm})\end{array}$} & \multicolumn{2}{|c|}{$\begin{array}{c}\text { Fresh } \\
\text { wt }(g)^{z}\end{array}$} & \multicolumn{2}{|c|}{$\begin{array}{c}\text { Dry } \\
\text { wt (g) }\end{array}$} & \multicolumn{2}{|c|}{$\begin{array}{l}\text { Leaves } \\
\text { (no.) }\end{array}$} & \multicolumn{2}{|c|}{$\begin{array}{c}\text { Strong } \\
\text { seedling index } \\
\end{array}$} \\
\hline & 0.30 & $b^{x}$ & 4.87 & c & 6.54 & b & 0.66 & b & 8.0 & b & 0.32 & b \\
\hline 20 & 0.35 & $\mathrm{a}$ & 6.21 & $\mathrm{a}$ & 13.27 & $\mathrm{a}$ & 1.27 & $\mathrm{a}$ & 9.2 & $\mathrm{a}$ & 0.67 & $\mathrm{a}$ \\
\hline 25 & 0.28 & $\mathrm{~b}$ & 5.52 & $\mathrm{~b}$ & 6.95 & $\mathrm{~b}$ & 0.66 & b & 6.6 & c & 0.23 & b \\
\hline
\end{tabular}

${ }^{\mathrm{z}}\left(1.8 \times{ }^{\circ} \mathrm{C}\right)+32={ }^{\circ} \mathrm{F}, 1 \mathrm{~cm}=0.3937$ inch, $1 \mathrm{~g}=0.0353 \mathrm{oz}$.

${ }^{\mathrm{y}}$ Strong seedling index $=$ stem diameter $($ measured in centimeters $) \times$ seedling dry weight $($ measured in grams $) \times$ leaf number/seedling height (measured in centimeters).

${ }^{x}$ Means within each column followed by different letters are significantly different according to the least significant difference test at $P \leq 0.05(\mathrm{n}=10)$.

Table 3. Effect of healing chamber relative humidity $(\mathrm{RH})$ on the survival rate of grafted cabbage seedlings grown in a growth chamber [at $20^{\circ} \mathrm{C}\left(68.0{ }^{\circ} \mathrm{F}\right)$ in darkness] with different $\mathrm{RH}$ values for $5 \mathrm{~d}(\mathbf{n}=30)$.

\begin{tabular}{lrrrrrr}
\hline & \multicolumn{7}{c}{ Time after grafting $(\mathbf{d})$} \\
\cline { 2 - 7 } RH (\%) & $\mathbf{3}$ & $\mathbf{5}$ & $\mathbf{6}$ & \multicolumn{9}{c}{$\mathbf{9}$} & $\mathbf{1 0}$ & $\mathbf{1 2}$ \\
\cline { 2 - 7 } 75 & 100.0 & 96.7 & 96.7 & 96.7 & 96.7 & 93.3 \\
85 & 100.0 & 100.0 & 100.0 & 100.0 & 100.0 & 100.0 \\
95 & 100.0 & 100.0 & 100.0 & 100.0 & 96.7 & 96.7 \\
\hline
\end{tabular}

96.7\% on days 10 and 12 after grafting (Table 5).

When the quality of ' $\mathrm{K}-\mathrm{Y}$ cross' grafted seedlings on day 35 after grafting was evaluated, the seedlings that had healed under high-light conditions had the greatest stem diameter, plant height, fresh weight, dry weight, leaf number, and strong seedling index (Table 6). Although there were no significant differences in plant height, dry weight, or leaf number between plants that had healed under high-light and dark conditions, the stem diameter, fresh weight, and strong seedling index of seedlings healed under the high-light condition were significantly greater than those of seedlings that had healed under dark conditions (Table 6). In summary, we believe that $20{ }^{\circ} \mathrm{C}, 95 \% \mathrm{RH}$, and a high-light environment provide the optimal healing conditions for cabbage.

HeAd TRAITS AND QUALITY. K$\mathrm{Y} / \mathrm{TJ}$ grafted plants formed mature heads similar to those of $\mathrm{K}-\mathrm{Y} / \mathrm{K}-\mathrm{Y}$ self-grafted plants (Fig. 2B). Next, we attempted to graft 'K-Y cross' cabbage to different chinese kale rootstocks and evaluate the head traits and quality. When the cabbage heads were harvested, we found no significant differences in head traits between $\mathrm{K}-\mathrm{Y} / \mathrm{K}-\mathrm{Y}$ self-grafted plants and ' $\mathrm{K}-\mathrm{Y}$ cross' nongrafted plants (Table 7). The contents of ascorbic acid, TSS, water, and chlorophyll were also not significantly different between ' $\mathrm{K}-\mathrm{Y}$ cross' self-grafted and nongrafted plants (Table 8). These results indicate that the grafting procedure itself did not change cabbage heading performance, but the head traits and head qualities of 'K-Y cross' grafted plants differed when different rootstocks were used (except for the head weight, head polar diameter, core length, water content, and total 
chlorophyll content). The head volume and equatorial diameter of the grafted plants were greatest when the 'Jen Chiau' rootstock was used (Table

7). The greatest head polar/equatorial ratio appeared when the 'Jung Ching' rootstock was used (Table 7 ), and the smallest core base width

Table 4. Effect of healing chamber relative humidity $(\mathrm{RH})$ on the subsequent growth of 35-d-old grafted cabbage seedlings.

\begin{tabular}{|c|c|c|c|c|c|c|c|c|c|c|c|c|}
\hline \multirow{2}{*}{$\frac{\mathrm{RH}(\%)}{75}$} & \multicolumn{2}{|c|}{$\begin{array}{c}\text { Stem } \\
\operatorname{diam}(\mathrm{cm})^{\mathrm{z}}\end{array}$} & \multicolumn{2}{|c|}{$\begin{array}{c}\text { Plant } \\
\text { ht }(\mathrm{cm})\end{array}$} & \multicolumn{2}{|c|}{$\begin{array}{c}\text { Fresh } \\
\text { wt }(g)^{\mathrm{z}}\end{array}$} & \multicolumn{2}{|c|}{$\begin{array}{c}\text { Dry } \\
\text { wt (g) }\end{array}$} & \multicolumn{2}{|c|}{$\begin{array}{c}\text { Leaves } \\
\text { (no.) }\end{array}$} & \multicolumn{2}{|c|}{$\begin{array}{l}\text { Strong } \\
\text { seedling index }\end{array}$} \\
\hline & 0.35 & $a^{x}$ & 5.55 & b & 10.46 & b & 1.10 & b & 8.7 & $\mathrm{a}$ & 0.62 & $\mathrm{a}$ \\
\hline 85 & 0.33 & $\mathrm{a}$ & 5.81 & $a b$ & 10.07 & b & 0.92 & c & 8.2 & $\mathrm{a}$ & 0.43 & b \\
\hline 95 & 0.35 & $\mathrm{a}$ & 6.21 & $\mathrm{a}$ & 13.27 & $\mathrm{a}$ & 1.27 & $\mathrm{a}$ & 9.2 & $\mathrm{a}$ & 0.67 & $\mathrm{a}$ \\
\hline
\end{tabular}

${ }^{\mathrm{z}} \mathrm{l} \mathrm{cm}=0.3937$ inch, $\mathrm{l} \mathrm{g}=0.0353 \mathrm{oz}$.

${ }^{y}$ Strong seedling index $=$ stem diameter $($ measured in centimeters $) \times$ seedling dry weight $($ measured in grams $) \times$ leaf number/seedling height (measured in centimeters).

${ }^{\mathrm{x}}$ Means within each column followed by different letters are significantly different according to the least significant difference test at $P \leq 0.05(\mathrm{n}=10)$.

Table 5. Effect of healing chamber light intensity on the survival rate of grafted cabbage seedlings grown in a growth chamber [with $95 \%$ relative humidity at $\left.20{ }^{\circ} \mathrm{C}\left(68.0^{\circ} \mathrm{F}\right)\right]$ under different light intensities for $5 \mathrm{~d}(\mathrm{n}=30)$.

\begin{tabular}{lrrrrrr}
\hline & \multicolumn{7}{c}{ Time after grafting (d) } \\
\cline { 2 - 7 } & \multicolumn{1}{c}{$\mathbf{3}$} & $\mathbf{5}$ & $\mathbf{6}$ & $\mathbf{9}$ & $\mathbf{1 0}$ & $\mathbf{1 2}$ \\
\cline { 2 - 7 } Light intensity $^{\mathbf{z}}$ & 96.7 & 96.7 & 96.7 & 96.7 & 96.7 & 96.7 \\
High & 96.7 & 96.7 & 96.7 & 96.7 & 93.3 & 93.3 \\
Low & 100.0 & 100.0 & 100.0 & 100.0 & 96.7 & 96.7 \\
Dark &
\end{tabular}

${ }^{\mathrm{z}} \mathrm{High}, 79$ to $107 \mu \mathrm{mol} \cdot \mathrm{m}^{-2} \cdot \mathrm{s}^{-1}$; low, 38.6 to $58.8 \mu \mathrm{mol} \cdot \mathrm{m}^{-2} \cdot \mathrm{s}^{-1}$; dark, $0 \mu \mathrm{mol} \cdot \mathrm{m}^{-2} \cdot \mathrm{s}^{-1}$.

Table 6. Effect of healing chamber light intensity on the subsequent growth of 35-d-old grafted cabbage seedlings.

\begin{tabular}{|c|c|c|c|c|c|c|c|c|c|c|c|c|}
\hline \multirow{2}{*}{$\begin{array}{l}\text { Light } \\
\text { intensity } \\
\text { High }\end{array}$} & \multicolumn{2}{|c|}{$\begin{array}{c}\text { Stem } \\
\operatorname{diam}(\mathrm{cm})^{y}\end{array}$} & \multicolumn{2}{|c|}{$\begin{array}{c}\text { Plant } \\
\text { ht }(\mathrm{cm})\end{array}$} & \multicolumn{2}{|c|}{$\begin{array}{c}\text { Fresh } \\
\text { wt }(g)^{y}\end{array}$} & \multicolumn{2}{|c|}{$\begin{array}{c}\text { Dry } \\
\text { wt (g) }\end{array}$} & \multicolumn{2}{|c|}{$\begin{array}{c}\text { Leaves } \\
\text { (no.) }\end{array}$} & \multicolumn{2}{|c|}{$\begin{array}{c}\text { Strong } \\
\text { seedling index }\end{array}$} \\
\hline & 0.41 & $a^{w}$ & 6.35 & $\mathrm{a}$ & 16.22 & $\mathrm{a}$ & 1.82 & $\mathrm{a}$ & 9.4 & $\mathrm{a}$ & 1.10 & $\mathrm{a}$ \\
\hline Low & 0.36 & $\mathrm{~b}$ & 5.76 & b & 10.63 & c & 1.29 & b & 8.3 & b & 0.66 & $b$ \\
\hline Dark & 0.35 & $\mathrm{~b}$ & 6.21 & a & 13.27 & b & 1.27 & a & 9.2 & a & 0.67 & $\mathrm{~b}$ \\
\hline
\end{tabular}

${ }^{\mathrm{z}} \mathrm{High}, 79$ to $107 \mu \mathrm{mol} \cdot \mathrm{m}^{-2} \cdot \mathrm{s}^{-1}$; low, 38.6 to $58.8 \mu \mathrm{mol} \cdot \mathrm{m}^{-2} \cdot \mathrm{s}^{-1} ;$ dark, $0 \mu \mathrm{mol} \cdot \mathrm{m}^{-2} \cdot \mathrm{s}^{-1}$.

${ }^{\mathrm{y}} 1 \mathrm{~cm}=0.3937$ inch, $1 \mathrm{~g}=0.0353 \mathrm{oz}$

${ }^{\mathrm{x}}$ Strong seedling index $=$ stem diameter $($ measured in centimeters $) \times$ seedling dry weight $($ measured in grams $) \times$ leaf number/seedling height (measured in centimeters)

${ }^{\mathrm{w}}$ Means within each column followed by different letters are significantly different according to the least significant difference test at $P \leq 0.05(\mathrm{n}=10)$. was observed when the 'Jie Lan' and 'Huei Jin' rootstocks were used (Table 7). Last, the lowest percentage head volume was found when the 'Jen Chiau' rootstock was used (Table 7). Although different head traits were found among different combinations of scion/rootstock grafting plants, there were no significant differences with the 'K-Y cross' nongrafted plants (Table 7).

In terms of head quality, the water content was similar among all grafted plants and ranged from $92.0 \%$ to $92.6 \%$ (Table 8 ). There were also no significant differences in the total chlorophyll content among different scion/rootstock combinations (Table $8)$. Interestingly, the heads of $\mathrm{K}-\mathrm{Y} / \mathrm{JL}$ grafted plants harbored the greatest ascorbic acid content and TSS content, and both parameters were significantly greater than in $\mathrm{K}-\mathrm{Y} / \mathrm{K}-\mathrm{Y}$ self-grafted plants and ' $\mathrm{K}-\mathrm{Y}$ cross' nongrafted plants (Table 8 ). These results imply that grafting ' $\mathrm{K}-\mathrm{Y}$ cross' on 'Jie Lan' results in better head quality.

\section{Discussion}

Oda et al. (1992) reported that cabbage scions could be grafted successfully onto kale or kohlrabi rootstocks, but their survival ratios were low $(5 \%$ to $20 \%)$. In contrast, our survival ratios [up to $93.3 \%$ (Tables 1,3 , and 5)] were much greater. Furthermore, as a result of early harvesting, the cabbage had not formed heads when kale or kohlrabi was used as the rootstock in the study by Oda et al. (1992). In contrast, cabbage

Table 7. Effects of different rootstocks on the head traits of grafted cabbage plants. ${ }^{\mathrm{z}}$

\begin{tabular}{|c|c|c|c|c|c|c|c|c|c|c|c|c|c|c|c|c|}
\hline \multirow{3}{*}{$\frac{{\text { Scion} / \text { rootstock }^{\mathrm{y}}}_{\mathrm{K}-\mathrm{Y} / \mathrm{JL}}}{}$} & \multicolumn{10}{|c|}{ Head } & \multicolumn{6}{|c|}{ Core } \\
\hline & \multirow{2}{*}{\multicolumn{2}{|c|}{$\mathrm{Wt}(\mathrm{g})^{\mathrm{x}}$}} & \multirow{2}{*}{\multicolumn{2}{|c|}{$\begin{array}{l}\text { Volume } \\
\left(\mathrm{cm}^{3}\right)^{\mathrm{x}}\end{array}$}} & \multicolumn{6}{|c|}{$\operatorname{Diam}(\mathrm{cm})^{x}$} & \multirow{2}{*}{\multicolumn{2}{|c|}{$\begin{array}{l}\text { Length } \\
(\mathrm{cm})\end{array}$}} & \multirow{2}{*}{\multicolumn{2}{|c|}{$\begin{array}{c}\text { Base } \\
\text { width }(\mathrm{cm})\end{array}$}} & \multirow{2}{*}{\multicolumn{2}{|c|}{$\begin{array}{c}\text { Volume } \\
\text { (\% head vol }\end{array}$}} \\
\hline & & & & & \multicolumn{2}{|c|}{ Polar (P) } & \multicolumn{2}{|c|}{ Equatorial (E) } & \multicolumn{2}{|c|}{$\mathrm{P} / \mathrm{E}$} & & & & & & \\
\hline $\mathrm{K}-\mathrm{Y} / \mathrm{HJ}$ & 456 & $\mathrm{~b}$ & 645 & bcd & 9.6 & $\mathrm{a}$ & 10.7 & $\mathrm{bc}$ & 0.91 & $\mathrm{ab}$ & 4.3 & $\mathrm{a}$ & 1.9 & $\mathrm{bc}$ & 0.65 & $\mathrm{~b}$ \\
\hline $\mathrm{K}-\mathrm{Y} / \mathrm{JG}$ & 521 & $a b$ & 783 & $\mathrm{abc}$ & 9.7 & $\mathrm{a}$ & 11.4 & $\mathrm{ab}$ & 0.86 & $\mathrm{ab}$ & 5.0 & a & 2.0 & $\mathrm{abc}$ & 0.65 & $\mathrm{~b}$ \\
\hline $\mathrm{K}-\mathrm{Y} / \mathrm{Tl}$ & 466 & $\mathrm{~b}$ & 670 & abcd & 9.3 & a & 10.8 & $a b c$ & 0.86 & $a b$ & 5.1 & $\mathrm{a}$ & 2.1 & $\mathrm{ab}$ & 0.85 & $a b$ \\
\hline $\mathrm{K}-\mathrm{Y} / \mathrm{CK}$ & 466 & $\mathrm{~b}$ & 667 & abcd & 9.3 & $\mathrm{a}$ & 10.8 & $a b c$ & 0.87 & $\mathrm{ab}$ & 5.2 & a & 2.0 & $a b c$ & 0.80 & $a b$ \\
\hline K-Y/JC & 463 & $\mathrm{~b}$ & 639 & $\mathrm{~cd}$ & 9.6 & a & 10.5 & c & 0.94 & $\mathrm{a}$ & 4.5 & $\mathrm{a}$ & 2.1 & $\mathrm{a}$ & 1.06 & $\mathrm{a}$ \\
\hline $\mathrm{K}-\mathrm{Y} / \mathrm{K}-\mathrm{Y}$ & 567 & a & 806 & $\mathrm{ab}$ & 9.7 & $\mathrm{a}$ & 11.6 & $\mathrm{ab}$ & 0.84 & $\mathrm{~b}$ & 4.7 & $\mathrm{a}$ & 2.1 & $a b$ & 0.66 & $\mathrm{~b}$ \\
\hline $\mathrm{K}-\mathrm{Y}$ & 488 & $a b$ & 678 & abcd & 9.7 & $\mathrm{a}$ & 10.9 & $a b c$ & 0.90 & $a b$ & 5.1 & $\mathrm{a}$ & 1.9 & $\mathrm{abc}$ & 0.75 & $a b$ \\
\hline
\end{tabular}

${ }^{\mathrm{z}}$ Sown on 17 Oct. 2014, grafted on 7 Nov. 2014, transplanted on 1 Dec. 2014, harvested on 2 May 2015.

'‘ K-Y cross' cabbage (K-Y), 'Jie Lan' chinese kale (JL), 'Huei Jin' chinese kale (HJ), 'Jung Gau' chinese kale (JG), 'Taichung No.l' chinese kale (Tl), 'Jen Chiau' chinese kale (JeC), 'Tsuei Jin' chinese kale (TJ), 'CK-7l' chinese kale (CK), 'Jung Ching' chinese kale (JC), 'K-Y cross' cabbage grafted onto 'K-Y cross' cabbage (K-Y/K-Y), 'K-Y cross' cabbage without grafting (K-Y).

${ }^{\mathrm{x}} \mathrm{l} \mathrm{g}=0.0353 \mathrm{oz}, 1 \mathrm{~cm}^{3}=0.0610$ inch $^{3}, 1 \mathrm{~cm}=0.3937$ inch.

${ }^{\mathrm{w}}$ Means within each column followed by different letters are significantly different by the least significant difference test at $P \leq 0.05(\mathrm{n}=4)$. 
Table 8. Effects of different rootstocks on the head qualities of grafted cabbage plants. $^{\text {. }}$

\begin{tabular}{|c|c|c|c|c|c|c|c|c|}
\hline \multirow{2}{*}{$\begin{array}{l}\text { Scion/ } \\
\text { rootstock } \\
\mathrm{K}-\mathrm{Y} / \mathrm{JL}\end{array}$} & \multicolumn{2}{|c|}{$\begin{array}{l}\text { Ascorbic } \\
\text { acid } \\
\left(\mathrm{mg} \cdot \mathrm{L}^{-1}\right)^{\mathrm{x}}\end{array}$} & \multicolumn{2}{|c|}{$\begin{array}{c}\text { Total } \\
\text { soluble } \\
\text { solids (\%) } \\
\end{array}$} & \multicolumn{2}{|c|}{$\begin{array}{c}\text { Water } \\
\text { content (\%) }\end{array}$} & \multicolumn{2}{|c|}{$\begin{array}{c}\text { Total } \\
\text { chlorophyll } \\
\left(\mathrm{mg} \cdot \mathrm{g}^{-1} \mathrm{FW}\right)^{\mathrm{x}}\end{array}$} \\
\hline & 370 & $a^{w}$ & 6.7 & $\mathrm{a}$ & 92.0 & $\mathrm{~b}$ & 10.6 & $a b$ \\
\hline $\mathrm{K}-\mathrm{Y} / \mathrm{HJ}$ & 328 & $a b c$ & 6.0 & $\mathrm{~b}$ & 92.1 & $a b$ & 9.7 & $\mathrm{~b}$ \\
\hline K-Y/JG & 318 & $\mathrm{bc}$ & 5.6 & bc & 92.3 & $a b$ & 13.9 & $a b$ \\
\hline $\mathrm{K}-\mathrm{Y} / \mathrm{Tl}$ & 347 & $\mathrm{ab}$ & 5.6 & $\mathrm{~b}$ & 92.4 & $a b$ & 14.5 & $a b$ \\
\hline K-Y/JeC & 311 & bcd & 5.8 & $\mathrm{~b}$ & 92.2 & $a b$ & 14.6 & $a b$ \\
\hline K-Y /TJ & 323 & $a b c$ & 5.1 & $\mathrm{c}$ & 92.4 & $a b$ & 12.8 & $a b$ \\
\hline $\mathrm{K}-\mathrm{Y} / \mathrm{CK}$ & 280 & cde & 6.0 & $b$ & 92.2 & $a b$ & 16.7 & $a b$ \\
\hline K-Y/JC & 246 & e & 5.6 & bc & 92.1 & $a b$ & 19.5 & $a b$ \\
\hline $\mathrm{K}-\mathrm{Y} / \mathrm{K}-\mathrm{Y}$ & 262 & de & 5.9 & $\mathrm{~b}$ & 92.6 & $\mathrm{a}$ & 14.8 & $a b$ \\
\hline $\mathrm{K}-\mathrm{Y}$ & 234 & $\mathrm{e}$ & 5.6 & bc & 92.3 & $a b$ & 25.3 & $\mathrm{a}$ \\
\hline
\end{tabular}

${ }^{\mathrm{z}}$ Sown on 17 Oct. 2014; grafted on 7 Nov. 2014; transplanted on 1 Dec. 2014; harvested on 2 May 2015.

' $\mathrm{K}-\mathrm{Y}$ cross' cabbage (K-Y), 'Jie Lan' chinese kale (JL), 'Huei Jin' chinese kale (HJ), 'Jung Gau' chinese kale (JG), 'Taichung No.l' chinese kale (T1), 'Jen Chiau' chinese kale (JeC), 'Tsuei Jin' chinese kale (TJ), 'CK-71' chinese kale (CK), 'Jung Ching' chinese kale (JC), 'K-Y cross' cabbage grafted onto 'K-Y cross' cabbage (K-Y/K-Y), 'K-Y cross' cabbage without grafting (K-Y).

${ }^{\mathrm{x}} \mathrm{l} \mathrm{mg} \cdot \mathrm{L}^{-1}=1 \mathrm{ppm}, 1 \mathrm{mg} \cdot \mathrm{g}^{-1}=1000 \mathrm{ppm}$.

${ }^{\mathrm{w}}$ Means within each column followed by different letters are significantly different by the least significant difference test at $P \leq 0.01(\mathrm{n}=4)$.

formed heads normally when chinese kale was used as the rootstock in our experiment (Table 7; Fig. 2B). Furthermore, the head weight of the grafted plants was similar to that of the nongrafted plants (Table 7). We suggest that the successful grafting of cabbage in our experiment may be the result of the factors discussed next. First, the scion/rootstock combination is different. Oda et al. (1992) used kale and kohlrabi as rootstocks, whereas we used chinese kale. A viable scion/rootstock combination is important for successful grafting. Second, the grafting methods were different. Oda et al. (1992) used cleft grafting, whereas we used tube grafting. The seedlings produced by tube grafting are often healthy and strong (Lee et al., 2010).Third, the seedling age used for grafting was different. Oda et al. (1992) proposed that the low survival ratio in their experiment was the result of the use of small seedlings, which are difficult to handle. In contrast, older seedlings, which are easier to handle, were used in our experiments. Last, better healing environments were selected in our experiment, which also contributed to the high survival ratios.

Traditionally, grafted plants are healed in a plastic tunnel with transparent film inside to maintain high humidity, and silver/white cheesecloth outside to provide shade (Lee et al., 2010; Oda, 2007). However, the survival rate and quality of grafted seedlings are inconsistent when the external environment changes. Previous reports have shown that grafted seedlings healed in highly controlled environments have greater survival rates, faster growth rates and better seedling quality (Jang et al., 2011; Nobuoka et al., 2005). In fact, various acclimatization chambers are commonly used by commercial companies in Japan and Korea (Lee et al., 2010). In Taiwan, an increasing number of commercial seedling industries are also using healing chambers to produce grafted tomato seedlings. Because high humidity is maintained by humidifiers in healing chambers, instead of manual application, labor can also be saved.

The optimal cabbage healing conditions $\left[20{ }^{\circ} \mathrm{C}, 95 \% \mathrm{RH}\right.$, and a high-light environment (Tables $1-$ $6)$ ] identified in this study could be applied to commercially grafted cabbage seedling production in the future with the healing chambers currently in use in the seedling industry. Previous studies have shown that the percentage of diseased grafted tomato plants may increase when the $\mathrm{RH}$ during the healing process is increased (Vu et al., 2013). Although we did not find any diseased plants in our experiments, high humidity (95\% $\mathrm{RH})$ conditions during the healing process in commercial grafted seedling production should be applied with caution. Previous studies have shown that grafted tomato and cucumber show better growth performance when the light intensity is greater during the healing stage (Jang et al., 2011; Nobuoka et al., 2005). Our results also showed the same pattern, with 'K-Y cross' grafted seedlings healed under high-light conditions exhibiting the best quality (Table 6). The better growth performance of grafted seedlings under high-light conditions may be the result of a greater photosynthetic rate.

The cabbage grafting method described in this research has the following advantages. First, it has a high grafting survival rate. Second, the identified best healing condition could be applied directly to commercial production using a healing chamber to produce stable seedlings with good quality. Third, the technique of plug seedlings is consistent with the major production methods used by seed companies. Fourth, the operation is simple and rapid. Fifth, this method can be performed, not only by hand, but also potentially by a grafting robot. This is an important feature because conventional manual grafting is laborious. Because tube grafting can be performed by machine (Lee et al., 2010), we assume the cabbage grafting method developed in this study has the potential for automatic production in the future. The development of grafting machines and robots for cucurbits and solanaceous crops (Kubota et al., 2008; Kurata, 1994; Lee and Oda, 2010; Lee et al., 2010) has enabled mechanization and automation. As the degree of mechanization increases, the popularity of grafting is expected to increase in the future.

In this study, grafting ' $\mathrm{K}-\mathrm{Y}$ cross' cabbage on 'Jie Lan' rootstock resulted in better head quality (Table 8 ). The success of cabbage grafting also indicates that additional benefits for production and fundamental research could be pursued; e.g., increased abiotic stress resistance, reduced pathogen infection, improved water and nutrient uptake, increased yield, flowering induction, scion-rootstock interaction studies, etc. Therefore, selecting the proper rootstock for diverse grafting purposes is an important next step. For example, 'K-Y cross' cabbage is popular in Taiwan but is susceptible to clubroot disease (a soil-borne disease caused by Plasmodiophora brassicae). Several clubrootresistant cultivars [e.g., 'YCR-NC34' and 'YCR-NC53' from Nippon Norin 
Seed Co., Ltd. (Tokyo, Japan)] may serve as rootstocks for ' $\mathrm{K}-\mathrm{Y}$ cross' cabbage. Grafting 'K-Y cross' cabbage onto resistant rootstocks may quickly solve the problem of clubroot disease, which is common in Taiwan, without requiring long breeding procedures to obtain a new resistant cultivar favored by Taiwanese consumers. Furthermore, the successful grafting of cabbage in this study indicates that this technique cannot only be used in cabbage, but also shows potential for additional vegetables within the Crucifer family. Given the high planting density used in cabbage production, the cost of grafted cabbage production may become a concern. However, the cost will be reduced dramatically when a grafting robot is developed in the future.

Also in the future, it is assumed that grafting will become more common in more areas. Indeed, vegetable grafting approaches that have been practiced for a long time in Asian countries such as Japan and Korea have already extended to European countries such as Spain and Italy, as well as the United States (Cantliffe, 2009; Kubota et al., 2008; Rivero et al., 2003). The development of grafting methods for more crops and the development of grafting machines for automation will encourage the spread of grafting technology more quickly to more countries.

In conclusion, this study developed a tube-grafting method for cabbage and identified the optimal healing conditions for cabbage $\left(20{ }^{\circ} \mathrm{C}, 95 \%\right.$ $\mathrm{RH}$, and high-light environment). Combining tube grafting with the best healing conditions can produce high survival rates and good quality of 'K-Y cross' grafted cabbage seedlings. Furthermore, the 'K-Y cross' grafted cabbage had comparable or even superior head quality when a specific rootstock was used.

\section{Literature cited}

Andrews, P.K. and C. Serrano Marquez. 1993. Graft incompatibility. Hort. Rev. 15:183-232.

Arnon, D.I. 1949. Copper enzymes in isolated chloroplasts: Polyphenoloxidase in Beta vulgaris. Plant Physiol. 24:1-15.

Cantliffe, D.J. 2009. Plug transplant technology. Hort. Rev. 35:397-436.
Chang, Y.-C. 2004. Effect of acclimatization environment condition on grafted seedlings growth of 'Asian No. 6' tomato. J. Chinese Soc. Hort. Sci. 50:405-420.

Chang, Y.-C., Y.-C. Chiu, and S. Chen. 2003. The study of acclimatization environmental condition on grafted seedlings of 'Empire No. 2' watermelon. J. Chinese Soc. Hort. Sci. 49:275-288.

Davis, A.R., P. Perkins-Veazie, R. Hassell, A. Levi, S.R. King, and X. Zhang. 2008a. Grafting effects on vegetable quality. HortScience 43:1670-1672.

Davis, A.R., P. Perkins-Veazie, Y. Sakata, S. López-Galarza, J.V. Maroto, S.-G. Lee, Y.-C. Huh, Z. Sun, A. Miguel, S.R. King, R. Cohen, and J.-M. Lee. 2008b. Cucurbit grafting. Crit. Rev. Plant Sci. 27:50-74.

Gaion, L.A., L.T. Braz, and R.F. Carvalho. 2017. Grafting in vegetable crops: A great technique for agriculture. Intl. J. Veg. Sci. 24(5):1-18.

Garnier, E. and G. Laurent. 1994. Leaf anatomy, specific mass and water content in congeneric annual and perennial grass species. New Phytol. 128:725-736.

Hartmann, H.T., D.E. Kester, F.T Davies, and R.L. Geneve. 2011. Plant propagation principles and practices. Prentice Hall, Upper Saddle River, NJ.

Ignatov, A., K. Hida, and Y. Kuginuki. 1998. Black rot of crucifers and sources of resistance in Brassica crops. Jpn. Agr. Res. Qrtly. 32:167-172.

Jang, Y., E. Goto, Y. Ishigami, B. Mun, and C. Chun. 2011. Effects of light intensity and relative humidity on photosynthesis, growth and graft-take of grafted cucumber seedlings during healing and acclimatization. Hort. Environ. Biotechnol. 52:331-338.

Kleinhenz, M.D. and A. Wszelaki. 2003. Yield and relationships among head traits in cabbage as influenced by planting date and cultivar: I. Fresh market. HortScience 38:1349-1354.

Kubota, C., M.A. McClure, N. KokalisBurelle, M.G. Bausher, and E.N. Rosskopf. 2008. Vegetable grafting: History, use, and current technology status in North America. HortScience 43:1664-1669.

Kurata, K. 1994. Cultivation of grafted vegetables II: Development of grafting robots in Japan. HortScience 29:240-244.

Lee, J.-M. 1994. Cultivation of grafted vegetables I: Current status, grafting methods, and benefits. HortScience 29:235-239.

Lee, J.-M., C. Kubota, S.J. Tsao, Z. Bie, P.H. Echevarria, L. Morra, and M. Oda. 2010. Current status of vegetable grafting: Diffusion, grafting techniques, automation. Scientia Hort. 127:93-105.
Lee, J.-M. and M. Oda. 2010. Grafting of herbaceous vegetable and ornamental crops. Hort. Rev. 28:61-124.

Mudge, K., J. Janick, S. Scofield, and E.E. Goldschmidt. 2009. A history of grafting. Hort. Rev. 35:437-493.

Nobuoka, T., T. Nishimoto, and K. Toi. 2005. Wind and light promote graft-take and growth of grafted tomato seedlings. J. Jpn. Soc. Hort. Sci. 74:170-175.

Nobuoka, T., M. Oda, and H. Sasaki. 1996. Effects of relative humidity, light intensity and leaf temperature on transpiration of tomato scions. J. Jpn. Soc. Hort. Sci. 64:859-865.

Oda, M. 2007. Vegetable seedling grafting in Japan. Acta Hort. 759:175-180.

Oda, M., M. Nagaoka, and K. Tsuji. 1992. Inter-generic, inter-specific and inter-varietal grafting in Cruciferae. Acta Hort. 319:425-430.

Oda, M. and T. Nakajima. 1992. Adhesive grafting of chinese cabbage on turnip. HortScience 27:1136.

Passam, H.C., M. Stylianou, and A. Kotsiras. 2005. Performance of eggplant grafted on tomato and eggplant rootstocks. Eur. J. Hort. Sci. 70:130-134.

Razaq, M., P. Zhang, and H.-L. Shen. Salahuddin. 2017. Influence of nitrogen and phosphorous on the growth and root morphology of Acer mono. PLoS One 12: e0171321.

Rivero, R.M., J.M. Ruiz, and L. Romero. 2003. Role of grafting in horticultural plants under stress conditions. Food Agr. Environ. 1:70-74.

Sakata, Y., T. Ohara, and M. Sugiyama. 2007. The history and present state of the grafting of cucurbitaceous vegetables in Japan. Acta Hort. 731:159-179.

Schwarz, D., Y. Rouphael, G. Colla, and J.H. Venema. 2010. Grafting as a tool to improve tolerance of vegetables to abiotic stresses: Thermal stress, water stress and organic pollutants. Scientia Hort. 127: 162-171.

Vu, N.-T., C.-H. Zhang, Z.-H. Xu, Y.-S. Kim, H.-M. Kang, and I.-S. Kim. 2013. Enhanced graft-take ratio and quality of grafted tomato seedlings by controlling temperature and humidity conditions. Protected Hort. Plant Factory 22:146153.

Xiang, B.-B., Y.-R. Zhu, W.J. Wang, Y.-L. Bai, and Y. Wang. 2011. Cell line screening of Catharanthus roseus for high yield production of ajmalicine. J. Med. Plants Res. 5:420-424. 


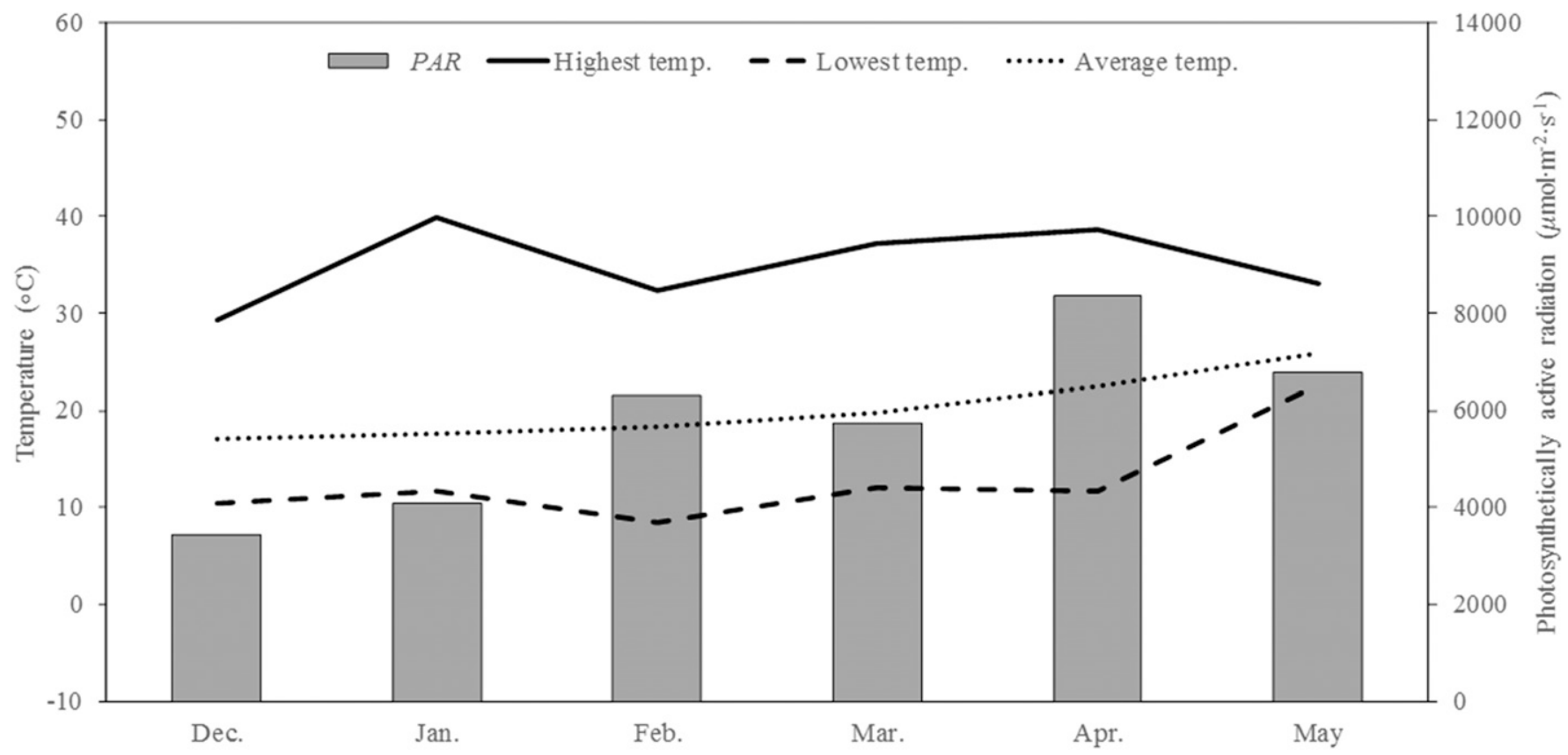

Supplemental Fig. 1. The meteorological data in the greenhouse (Dec. 2014 to May 2015) during the cultivation period of grafted cabbages. $P A R=$ photosynthetically active radiation; $\left(1.8 \times{ }^{\circ} \mathrm{C}\right)+32={ }^{\circ} \mathrm{F}$. 